\title{
RADIATION BLISTERING OF STRUCTURAL MATERIALS FOR FUSION DEVICES AND REACTORS
}

by

S. K. Das and M. Kaminsky

\section{NOTICE}

This report was prepared as an account of work sponsored by the United States Government. Neither the United States nor the Unite States Atomic Energy Commission, nor any of their employees, nor any of their contractors, subcontractors, or their employees, makes any warranty, express or implied, or assumes any makes any warranty, express or implied, or assumes any legal hiability or responsibility for the accuracy, completeness or usefulness of any information, apparatus, product or process disclosed, or represents that its use would not infringe privately owned rights.

\footnotetext{
Presented at:

Conference on Surface Effects in Controlled Thermonuclear Fusion Devices and Reactors, Argonne National. Laboratory, Argonne, Illinois, January 10-12, 1974
} 
Paper presented at Conference on "Surface Effects in Controlled Thermonuclear Fusion Devices and Reactors" held at Argonne National Laboratory January 10-12, 1974 (to appear in Proceedings).

RADIATION BLISTERING OF STRUCTURAL MATERIALS FOR FUSION DEVICES AND RE'ACTORS ${ }^{\dagger}$

\author{
S. K. Dac and M. Kamimals; \\ Argonne National Laboratory, Argonne, Illinois 60439
}

\title{
$\because$
}

$\underline{\text { Absiract }}$

Radiation blistering can be an important erosion process when the structural components of controlled thermonuclea fusion devices or reactors are exposed to the impact of energetic particles leaving the plasma region. A brief review of some of the important parameters governing the radiation blistering process is given. Erosion rates associated with helium blistering in V, Nb and Type 304 stainless steel are reported for different irradiation temperatures and different projectile energies.

\section{Introduction}

During the operation of thermonuclear devices and reactors, the surfaces of such major components as container walls, beam limiters, diverter walls, and beam-dump walls of the injector region will be exposed both to the primary plasma radiations and to secondary radiations from $(n, \gamma),(n, p),(n, a)$, and other nuclear reactions and from various secondary-particle and photon-emission phenomena induced by the primary radiation. For example, during the operation of a large steacy-state D-T fusion reactor, the vacuum walls are expected to reach $400-1000^{\circ} \mathrm{C}$ and simultaneously will be bombarded with high fluxes of energetic neutral particles (e.g., $\mathrm{MeV}$ neutrons and also neutral atoms formed by such processes as charge exchange near the plasma boundary), energetic ions leaking out of the confining fields, and energetic photons (e.g., Yrays, bremsstrahlung, soft $x$-rays, and synchrotron radiation). Such energetic radiations striking the surfaces of reactor components can cause plasma contamination and wall erosion by a variety of surface phenomena as discussed earlier $(1-3)$.

ine $u_{1}$ ine more important erosion processes has been identified to be radiation blistering $(1-5)$. In this process the gaseous atoms implanted in near surface 
regions by energetic projectiles form gas bubbles. Such bubbles near the surface region can grow, and when the pressure is high enough, they can plastically deform the surface skin to form visible blisters that may eventually rupture. The bursts of gas released by blister rupture can contaminate the plasma and peeling of the blister

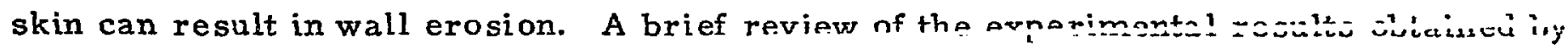
the a uthors on the importance of various parameters influencing the blistering process will be given in this paper.

\section{Experimental Procedures}

The target materials used for irradiations were of high purity (Marz grade) and were obtained from Materials Research Corporation, except for the Type 304 stainless steel samples which were of commercial grade. All targets were first mechanically polished and then electropolished by tèchniques described earlier $(4-9)$. The targets were annealed at appropriate temperatures in high vacuurn whenever required (4-9). All irradiations were done with a mass analyzed beam of ${ }^{4} \mathrm{He}^{+}$or $\mathrm{D}^{+}$ ions from a $2-\mathrm{MeV}$ Van de Graaff accelerator and the vacuum in the target chamber was $\sim 1-2 \times 10^{-8}$ Torr during the irradiation. Other details of target irradiation and examination of the irradiated surfaces zan be found elsewhere (4-9).

\section{Type of Projectile:}

In a $\mathrm{D}-\mathrm{T}$ fusion reactor the energetic projectiles such as deuterium, tritium and helium will strike structural components. Since the permeability of the hydrogen isotopes in most metals is quite different from that of the inert gas atoms like helium, it is important to study the effect these different projectiles have on the blistering process. Figures $1(a)$ and $1(b)$ compare the blisters formed in niobium irradiated at $700^{\circ} \mathrm{C}$ with ${ }^{4} \mathrm{He}^{+}$and $\mathrm{D}^{+}$ions, respectively. The blisters formed during helium-ion irradiation (Eig. 1a) after a total dose of $1.0 \mathrm{C} / \mathrm{cm}^{2}$ are of two types. The larger size blisters have an average diameter of 5-8 $\mu \mathrm{m}$, while the smaller size blisters have an average diameter of $\sim 0.5 \mu \mathrm{m}$. The blisters formed during deuteron irradiation after even a higher dose of $2.0 \mathrm{c} / \mathrm{cm}^{2}$ are also of two types, but are much smaller in size (Fig. 1b) than the helium blisters. The deuterium blisters appea $r$ in different shapes depending upon the orientation of the grains [e.g., dome shaped (10). elongated, crow-foot shaped (6) ]. Most of the deuterium blisters are unruptured (Fig. Ib) whereas some of the large helium blisters have ruptured. The observation 

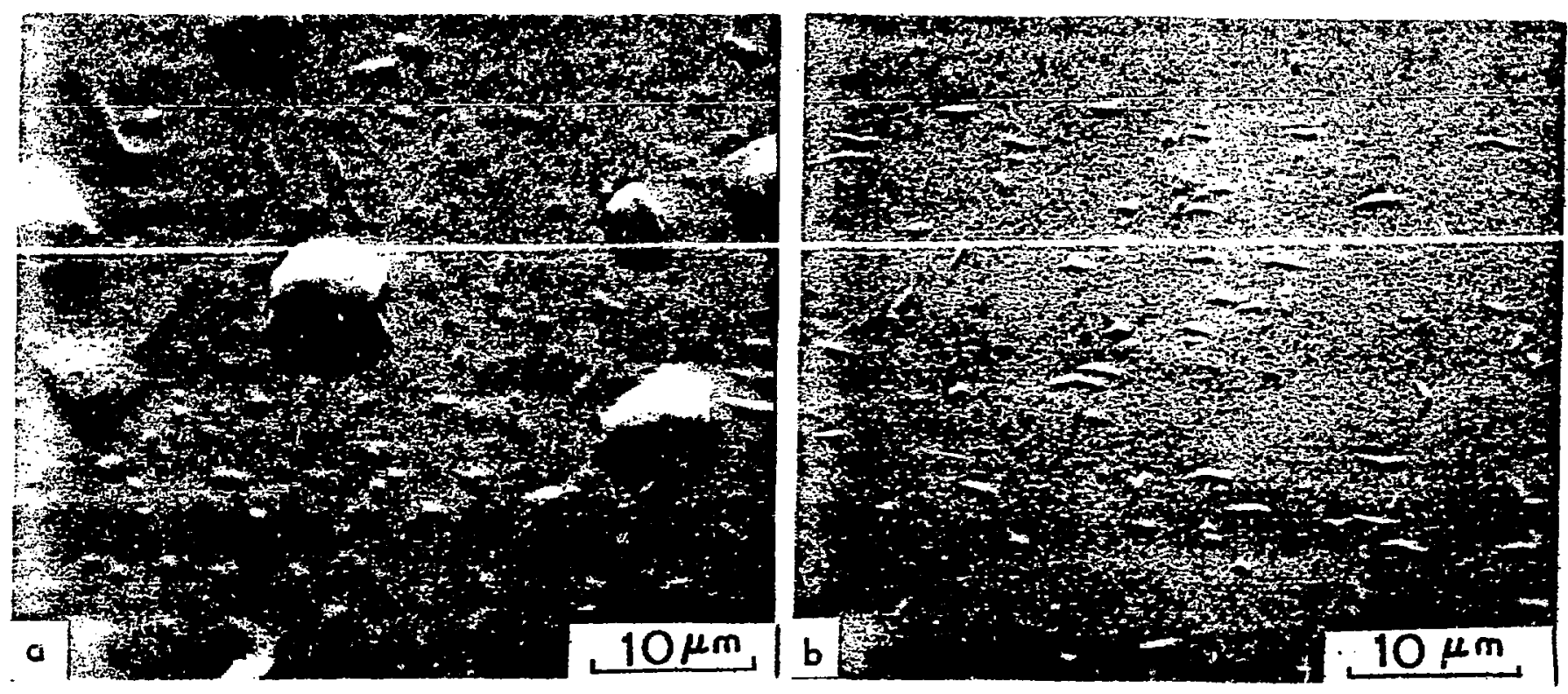

FIG. 1

Scanning electron micrograptis (SEMs) of annealed polycrystalline niobium surfaces irradiated at $700^{\circ} \mathrm{C}$ (a) with $0.5-\mathrm{MeV}{ }^{4} \mathrm{He}^{+}$ions to a total dose of $1.0 \mathrm{C} / \mathrm{cm}^{2}$ (b) with $0.25-\mathrm{MeV} \mathrm{D}^{+}$ions to a total dose of $2.0 \mathrm{C} / \mathrm{cm}^{2}$.

that blister size for deuteron ir radiation is smaller than for helium ion irradiation under nearly comparable conditions (note that the dose for deuteron irradiation was higher) can be related to the fact hat the gas buildup is greatly reduced for deuterium in niobium since the deuterium permeability (determined by the solubility and diffusivity) is many orders of magnitude larger than that of helium. For example, the diffusion coefficient of deuterium in niobium (11) is $D_{D}=1.3 \times 10^{-4} \mathrm{~cm}^{2} / \mathrm{sec}$ at $800^{\circ} \mathrm{C}$, while that for helium in niobium (12) ranges from $10^{-19}$ to $10^{-14} \mathrm{~cm}^{2} / \mathrm{sec}$ between the temperatures of $600^{\circ} \mathrm{C}$ and $1200^{\circ} \mathrm{C}$.

\section{Energy of Projectile}

Figures $2(a)$ to $2(f)$ illustrate the effect of projectile energy on helium blister formation in niobium irradiated at room temperature. Irradiation to a dose of $0.5 \mathrm{C} / \mathrm{cm}^{2}$ with $100-\mathrm{keV}^{4} \mathrm{He}^{+}$ions results in a blister density of $\sim 2 \times 10^{6} \mathrm{blisters} / \mathrm{cm}$, and the average blister diameter ranges from 1 to $30 \mu \mathrm{m}$ (Fig. 2a). Many of the large blisters show exfoliated skins and in some cases (marked by arrows) a second blister skin has ruptured and falien off. Figure $2(\mathrm{~b})$ shows an enlarged view nf a blister skin from which the skin thickness can be estimated to be $\sim 0.4 \mathrm{~km}$. Irradiation with $250-\mathrm{keV}^{4} \mathrm{He}^{+}$ions to the same dose of $0.5 \mathrm{C} / \mathrm{cm}^{2}$ showed blisters with average 
diameters ranging from 3 to 30 um and the blister density was $\sim 1.2 \times 10^{6} \mathrm{blisters} / \mathrm{cm}^{2}$. For $0.5-\mathrm{MeV}^{4} \mathrm{He}^{+}$ion irradiation to a total dose of $1.0 \mathrm{C} / \mathrm{cm}^{2}$ a very large blister (Fig. 2c) occupied about two-thirds of the bombarded area. From an enlarged view of a portion of the ruptured skin shown in Fig. $2(d)$ the skin thickness is determined to be

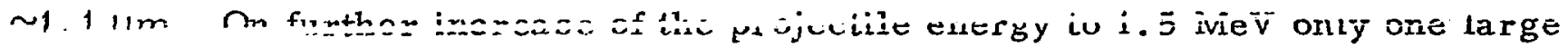
blister occupied the entire bombarded area (Fig. $2 e$ ). A portion of the ruptured skin can be seen in Fig. 2(f) and the skin thickness is found to be $\sim 2.8 \mu \mathrm{m}$. From a comparison of the blister skin thicknesses for different helium ion energies (Figs. 1b, $1 \mathrm{~d}$, and $1 \mathrm{f}$ ) it is clear that the blister skin thickness is increasing with increasing projectile energy. The measured skin thicknesses for different projectile energies fall within $30 \%$ of the corresponding projected ranges calculated according to Schi $\phi t t$ (13).

The increase in blister size with increase in projectile energy can be understood if one considers the expressions for the gass pressure "p" inside a blister as discussed earlier (4). The pressure " $\mathrm{p}$ " is directly proportional to the slin thickness " $t$ " and inversely proportional to the square of the radius "a" of the blister. Hence for a given blister" height " $h$ " and pressure " $p$ " (which is roughly porporional to the total dose), a higher projectile energy (and correspondingly higher skin thickness " $t$ ") will require a larger blister radius "a". At high temperature (e. g., niobium at $900^{\circ} \mathrm{C}$ ) the effect of projectile energy on blist $=r$ size is less pronounced. It should be pointed out that the erosion rates $S$ estimated by techniques described earlier $(4,5)$ for $100-\mathrm{keV}$ and $0.5-\mathrm{MeV}$ helium ion irradiations (see Figis. 1 a and $1 \mathrm{c}$, respectively) yield values of $S \sim 1.0 \pm 0.4$ and $S \sim 0.20 \pm 0.05$ niobium atoms per incident helium ion, respectively. Such an increase in erosion rate with decreasing projectile energy has also been observed for Type 304 stainless steel $(9,14)$.

\section{Total Dose and Dose Rate}

It has been observed $(6-8)$ that for helium ion irradiation of niobium the blister size increases with increasing total dose. Figures 3(a), 3(b) and 3(c) show blisters formed in Type 304 stainless steel irradiated at $450^{\circ} \mathrm{C}$ with $0.5-\mathrm{MeV}^{4} \mathrm{He}^{+}$ions to total doses of $0.1,0.5$ and $1.0 \mathrm{c} / \mathrm{cm}^{2}$, respectively. For a dose of $0.1 \mathrm{C} / \mathrm{cm}^{2}$ the average blister diameter is $\sim 700 \mu \mathrm{m}$ (Fig. 3a) and a large portion of the irradiated area is occupied by this single blister. At a higher dose of $0.5 \mathrm{c} / \mathrm{cm}^{2}$ three exfoliated skin iayers are observed (Fig. $3 b$ ) as compared with one for a dose of $0.1 \mathrm{C} / \mathrm{cm}^{i}$ (Fig. $3 a$ ). For an even higher dose of $1.0 \mathrm{C} / \mathrm{cm}^{2}$ the number of exfoliated layers increases to five 

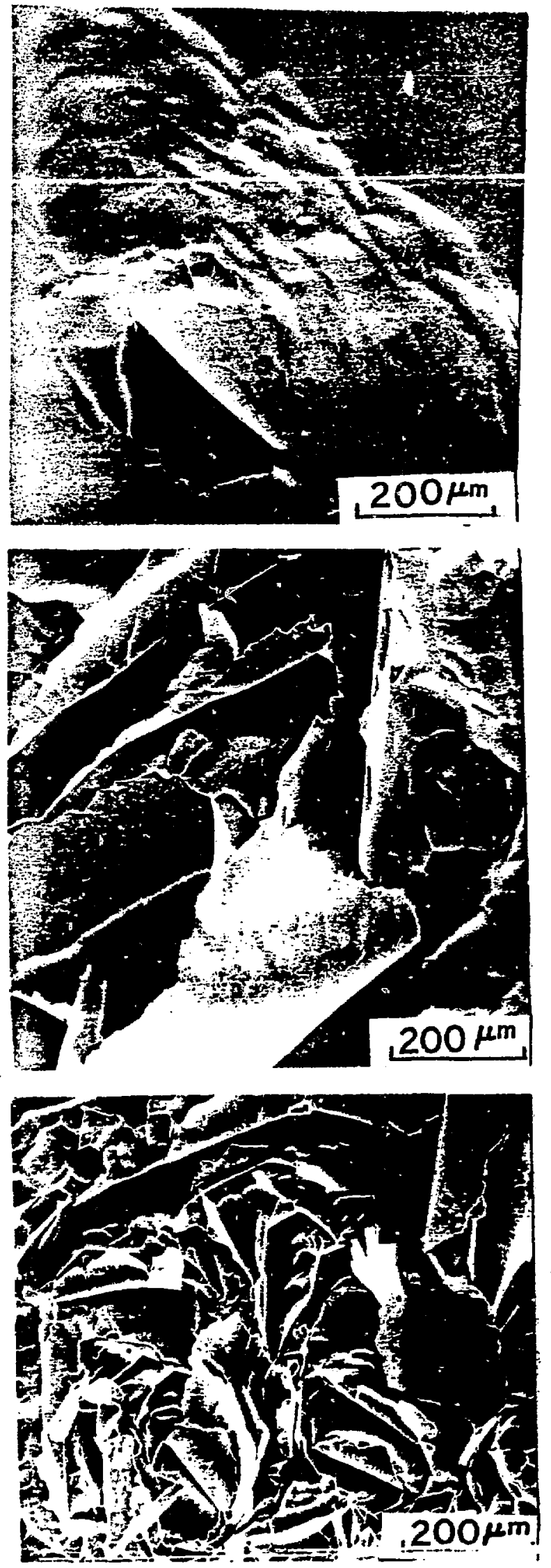

FIG. 3

SEMs of surfaces of annealed Type 304 stainless steel after irradiation at $450^{\circ} \mathrm{C}$ with $0.5-\mathrm{MeV}{ }^{4} \mathrm{He}^{+}$ions for dotal doses of (a) $0.1 \mathrm{C} / \mathrm{cm}^{2}$ (b) $0.5 \mathrm{C} / \mathrm{cm}^{2}$ and (c) 1. $0 \mathrm{C} / \mathrm{cm}^{2}$.

in some regions (Fig. 3c). The estimated erosion rates for the chree doses $0.1,0.5$ and $1.0 \mathrm{C} / \mathrm{cm}^{2}$ are $0.1 \pm 0.05,0.45 \pm 0.1$ and $0.8 \pm 0.2$ atoms per incident ion, respectively. One should note that within the experimental error the erosion rates depend nearly linearly on the dose. One should keep in mind that these rates a re determined only from that part of the blister skin which has been totaliy lost. Therefore the observed increase in the erosion rates with increasing dose (for the dose range studied here) is related to the increase in the exfoliation of blisters and to the subsequent loss of blister skin with increasing dose.

\section{The effect of total dose on} the blister size is less pronounced at high target temperature (e.g., $\mathrm{Nb}$ or $\mathrm{V}$ at $900^{\circ} \mathrm{C}$ ) than at room temperature $(6,15)$. For example, for annealed polycrystalline vanadium irradiated at $900^{\circ} \mathrm{C}$ with $0.5-\mathrm{MeV}$ ${ }^{4} \mathrm{He}^{+}$ions one observes that as the dose is increased by one order of magnitude from 0.1 to $1.0 \mathrm{c} / \mathrm{cm}^{2}$ the mean value of the average blister diameters shows (15) only a slight increase from 6.2 to $7.4 ! \mathrm{lm}$. This is in part due to a higher rate of helium 
release at $900^{\circ} \mathrm{C}$ than at room temperature (16). This effect of temperature will be discussed later.

At a particular irradiation temperature the rate of gas buildup near the implant depth and the subsequent blister formation will depend on the dose rate (i.e.,

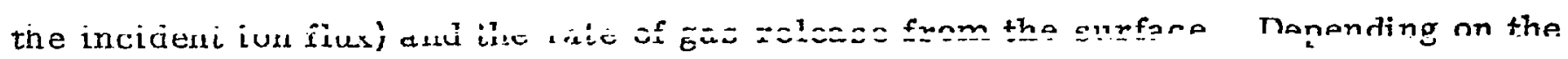
balance of gas trapping and gas release, there may or may not be an effect of dose rate on blister formation. Recent results on blistering in helium implanted vanadium show (15) that with increasing dose rate from $1 \times 10^{15}$ ions $/\left(\mathrm{cm}^{2}-\mathrm{sec}\right)$ the blister density increases from $(1.0 \pm 0.5) \times 10^{4}$ to $(7 \pm 2) \times 10^{4}$ blisters $/ \mathrm{cm}^{2}$. For deuterium blistering in niobium the effect of dose rate is found to be much more pronounced than for helium blistering for similar irradiation conditions. An increase in the dose rate has also been observed (i7) to reduce the critical dose for blister formation in proton irradiated molybdenum.

\section{Target Temperature.}

The target temperature is one of the most important parameters affecting blister formation. Figure $4 \mathrm{~A}$ shows a plot of the erosion rates vs. ta rget temperature for helium blistering of Type 304 stainless steel. It can be seen in Fig. $4 A$ that the maximum erosion rate occurs at an irradiation temperacure of $\sim 450^{\circ} \mathrm{C}$. A qualitatively similar temperature dependence has been observed for Type 316 stainless steel (18). Another striking result that is apparent from Fig. $4 \mathrm{~A}$ is that as the projectile ene rgy is reduced from $0.5 \mathrm{MeV}$ to $100 \mathrm{keV}$ the erosion rate increases by approximately a factor of 7 for the same dose of $0.5 \mathrm{C} / \mathrm{cm}^{2}$ and a temperature of $\sim 450^{\circ} \mathrm{C}$. Figure $4 \mathrm{~B}$ shows the effect of temperature on the blister formation in polycrystalline vanadium irradiated with $0.5-\mathrm{MeV}^{4} \mathrm{He}^{+}$ions for the same dose of $1.0 \mathrm{C} / \mathrm{cm}^{2}$. As the irradiation temperature is increased from room temperature to $300^{\circ} \mathrm{C}$ the number of exfoliated skin layers increases from one to two (c.f. Figs. $4 \mathrm{a}$ and $4 \mathrm{~b}$ ). Irradiation at $500^{\circ} \mathrm{C}$ shows (Fig. $4 \mathrm{C}$ ) an even stronger increase in blister exfoliation since six exfoliated slrir layers are observed in certain regions. On further increasing the irradiation temperature to above $800^{\circ} \mathrm{C}$ blisters (Fig. 4d) with average diameters of only 10-20 $\mathrm{\mu m}$ and with no large scale exfoliation are observed. The erosion rate appears to be at a maximum somewhere between $300^{\circ} \mathrm{C}$ and $500^{\circ} \mathrm{C}$.

Ine oisterveu cisangen e rusiun rales wlill lemperature is reiated is ilse strong temperature dependence of the yield strength of the material. For example, the 


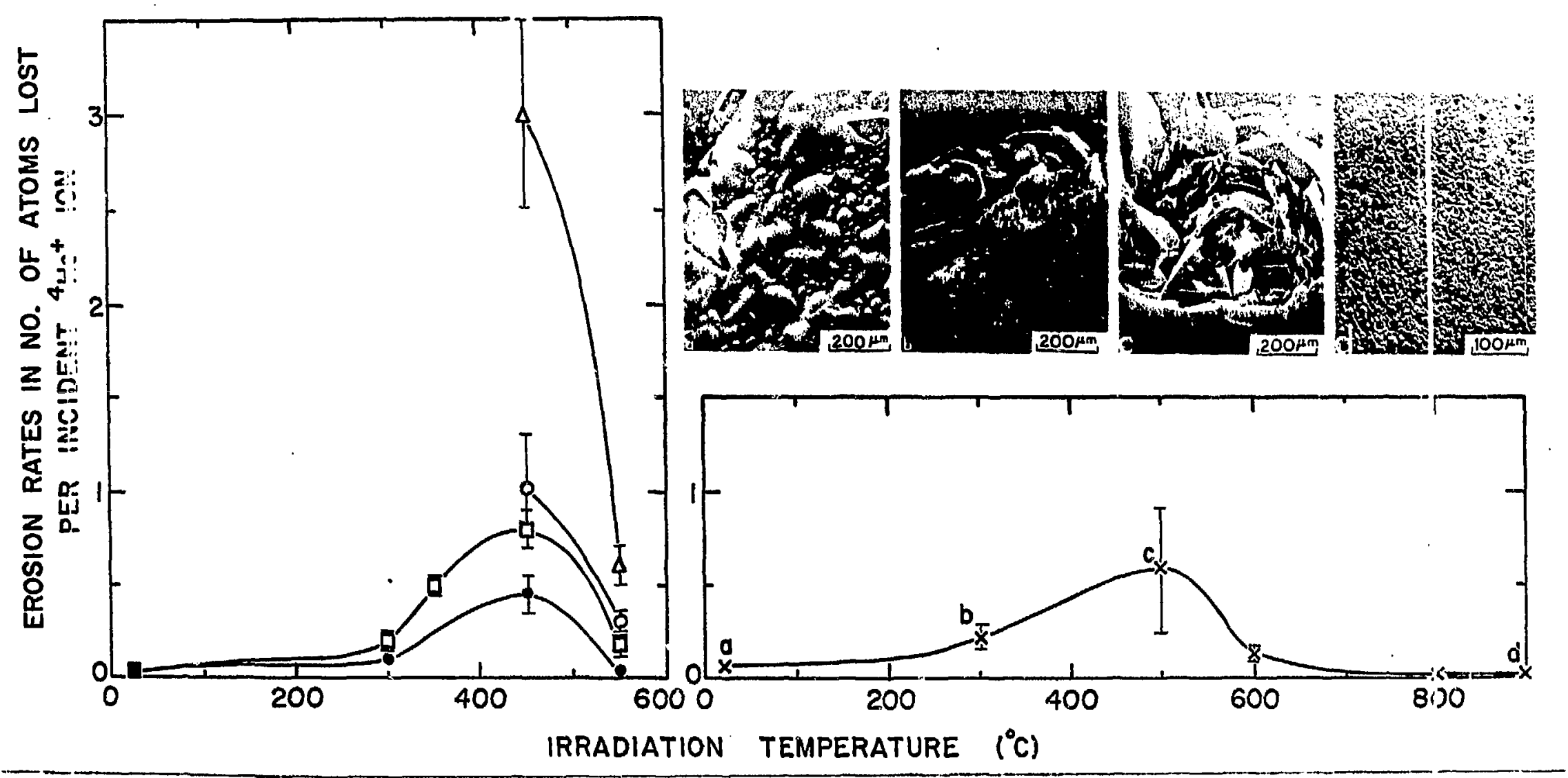

FIG. 4

(A) Erosion rates for annealed Type 304 stainless steel as a function of irradiation temperature for di.ferent projectile energie:s and total doses; : $0.5 \mathrm{C} / \mathrm{cm}^{2}$ with $0.5-\mathrm{MeV}^{4} \mathrm{Het}^{+}: 1.0 \mathrm{C} / \mathrm{cm}^{2}$ with $0.5-\mathrm{MeV}^{4} \mathrm{He}^{+},: 0.1 \mathrm{C} / \mathrm{cm}^{2}$ with 100-kei ${ }^{4} \mathrm{He}^{+}$, : $0.5 \mathrm{C} / \mathrm{cm}^{2}$ with $100-\mathrm{keV}^{4} \mathrm{He}^{+}$. (B) Erosion rates for annealed polycrystalline vanidiurn as a functicn of irradiation temperature for $0.5-\mathrm{MeV}^{4} \mathrm{He}^{+}$ions and for a cotal dose of $1.0 \mathrm{C} / \mathrm{cm}^{2}$. The figures (a) $-(\mathrm{d})$ at the top of Fig. ( B) show SEMs of irradiated surfaces for the temperatures indicated the rein. 
yield strength of anncaled 304 stainless steel at $450^{\circ} \mathrm{C}$ is half of its value at room temperature (19). Similariy the tensile strength of annealed vanadium at $900^{\circ} \mathrm{C}$ is less than a third of its value at room temperature (20). Thus, for a particular dose the collected gas in a bubble can deform the surface skin more readily at high temperature

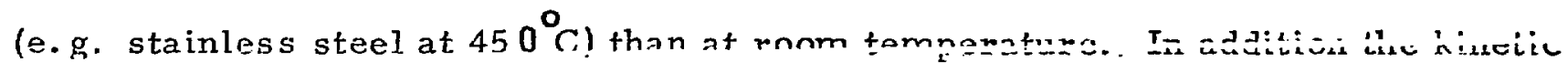
pressure of the gas in the bubble will increase with temperature and may also enhance this process. However, at very high temperatures (e.g. at $900^{\circ} \mathrm{C}$ for vanadium) helium may be released through the surface either by atomic diffusion or by migration of small bubbles. Some recent work (21) shows that helium bubtle mobility in niobium at $950^{\circ} \mathrm{C}$ is at least two orders of magnitude higher than that calculated earlier by Martin (22). Mass spectrometric evidence for helium release for niobium, vanadium and 316 stainless steel has been reporited $(16,18)$. Furthermore, at high temperatures partial annealing of the lattice defects may occur and thereby reduce the nucleation and growt: rate of the helium bubbles. Therefore, the amount of helium trapped in the lattice wi?l be affected by the helium release rate and the bubble nucleation rate and will in turn determine the size and density of helium bubbles and the subsequent blister size. Thus the degree of blistering and exfoliation of blister skin is maximized if the temperature is high enough so that the surface can be deformed easily (lower yield stress) but low enough so that the helium release from the surface is still very small.

The critical dose for the appearance of blisters is strongly temperature dependent. For example, for helium bombardment of annealed polycrystalline niobium. at room temperature for a total dose of $0.1 \mathrm{C} / \mathrm{cm}^{2}$ no blisters could be detected (4); but blisters were readily detected (6) for $900^{\circ} \mathrm{C}$ irradiation even after a dose of only $0.01 \mathrm{C} / \mathrm{cm}^{2}$. This temperature dependence of critical dose for blister appearance is also related to the temperature dependence of yield strength as discussed above.

\section{Other Parameters}

In addition to the parameters discussed above there are many other parameters that affect the degree of blistering and only a few will be mentioned here. Recent experiments (7) on helium blistering in cold worked and annealed niobium and vanadium show that for room temperature irradiation the blister size and the degree of blistering is reduced by cold working. Cold working has also been observec to reduce is v viu llumber density in neutron irradiated stainless steel $(23,24)$, but the void size does not change very much. However, for irradiation at $900^{\circ} \mathrm{C}$, the degree of 
blistering is similar for cold worked and annealed samples for both vanadium and niobium.

In bombarding monocrystalline metals with helium ions or deuterons, it has been observed (25) that the blister shape and the orientation of the blisters with respect to each other depend strongly on the crystallographic orientation of the irradiated surface plane of the target. The shapes of blisters formed on the (111), (110) and (001) surface planes of monocrystalline niobium samples irradiated at $900^{\circ} \mathrm{C}$ with axially channeled $0.5-\mathrm{MeV}^{4} \mathrm{He}^{+}$ions have been related to the intersection of certain active slip planes with the surface plane of the monocrystal during blister formation (25). It has also been observed that for the helium blisters formed on monocrystals the blister size is greater if the projectiles are axially channeled than if they were unchanneled $(8,17,25)$. The blister density in helium implanted (111) niobium monocrystals irradiated at $900^{\circ} \mathrm{C}$ has been observed to decrease by approximately two orders of magnitude for the channeled helium projectiles as compared to the unchanneled ones (26). Such a behavior is not unexpected since the channeling of projectiles helps to reduce the radiation damage in near surface regions (corresponding to the initial part of the trajectory of the channeled projectiles) and thereby reduces the number of radiation induced nucleation sites for bubble formation.

\section{Conclusion}

The material presented in this paper suggests that helium blistering should be considered a serious erosion process for such fusion devices and reactor components as containe $x$ walls, direct converter surfaces, diverter surfaces, and beam limiters. For example, from the erosion rates quoted above for 304 stainless steel for $100-\mathrm{keV} \mathrm{He}^{+}$ion irradiation to a total dose of $0.5 \mathrm{C} / \mathrm{cm}^{2}$ at $450^{\circ} \mathrm{C}$ an annual thickness loss of about $0.09 \mathrm{~mm}$ per year can be estimated for a helium flux of $1 \times 10^{13}$ projectiles $\mathrm{cm}^{-2} \mathrm{sec}^{-1}$. As has been pointed out earlier (5) such annual thickness loss values will be enhanced by the vaporization of the blister skin due to heating by energetic photon absorption (e.g. bremsstrahlung). Furthermore, it should be pointed out that our results on the temperature dependence of helium blistering of niobium and stairless steel indicate that the low wall temperatures considered by some authors for the

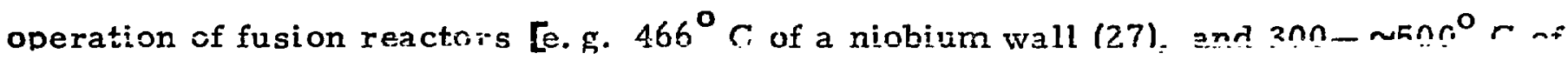
a stainless steel wall (28)] would lead to significantly more wall erosion than if such surfaces would be operated at a higher, more optimum wall temperature (e. g. $\sim 900^{\circ} \mathrm{C}$

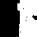


for niobium). Work is in progress to find ways to reduce the helium blistering process by choice of materials and their st uctures (e.g. porous materiais).

\section{Acknowledgments}

The a uthors would like to thank Mr. P. Dusza, Mr. T. Dettweiler, Mr. M. Kral, and Mr. W. Aykens for their help during the experiments.

\section{References}

† Work performed under the auspices of U.S. Atomic Energy Commission.

1. M. Kaminsky, IEEE Trans. Nucl. Sci., 18, 208 (1971).

2. M. Kaminsky, in Proceedings of the International Working Sessions on Fusion Reactor Technology, Oak Ridge National Laboratory; Oak Ridge, Tennessee, 1971, U. S. Atomic Energy Commission Report No. CONF-719624 p. 86 (1971).

3. M. Kaminsky, in Proceedings of the 7th Symposium on Fusion Technology, 24-27 October 1972, Grenoble, France, (Commission of the European Communities, Luxembourg, 1972), p. 41.

4. S. K. Das and M. Kaminsky, J. Appl. Phys., 44, 25 (1973).

5. S. K. Das and M. Kaminsky, in Proceedings of the Texas Symposium on the Technology of Controlled Thermonuclear Fusion Experiments and the Engineering Aspects of Fusion Reactors, 20-22 November 1972, Austin, Texas (USAEC, National Technical Information Service, Springfield, Virginia 22151, to be published).

6. M. Kaminsky and S. K. Das, Rad. Effects, 18, 245 (1973).

7. S. K. Das and M. Kaminsky, in Defects and Defect Clusters in B.C.C. Metals and their Alloys, Nuclear Metallurgy Vol. 18, edited by R. J. Arsenault, National Bureau of Standards, Gaithersburg, Maryland, p. 240 (1973).

8. S. K. Das and M. Kaminsky, J. Appl. Phys., 44, 2520 (1973).

9. S. K. Das and M. Kaminsky, IEEE Trans. Nucl. Sci,

10. J. M. Donhowe and G. L. Kulcinski, is Fusion Reactor First Wall Materials, ed.

L. C. Ianiello, USAEC Report No. WASH-1206, 1972, p. 75.

11. G. Schaumann, J. Völkl and G. Alefeld, Phys. Stat. Sol 42, 401 (1970).

12. S. Blow, J. Brit Nucl. Energy Soc.. 11, 371 (1972).

13. M. E. Schiфtt, Mat. Fys. Medd. Dan. Vid. Selsk 35, no. 9, (1966).

14. M. Kaminsky and S. K. Das, Nucl. Tech.

(1974).

15. S. K. Das and M. Kaminsky, Paper presented at International Conference on "Apöicaiimas vi ius iveams to ivetals" held at Albuquerque, New Mexico, October 2-4, 1973, to be published by Plenum Press, New Yoxk.

16. W. Bauer and G. J. Thomas in Ref. 7, p. 255. 
17. H. Verbeek and W. Eckstein in Ref. 14.

18. W. Bauer and G. J. Thomas, J. Nucl. Mat. 47, 241 (1973).

19. K. F. Smith in Reactor Handbook vol. 1, Interscience Publishers, N. Y., p. 563 (1960).

20. J. R. Keeler and K. F. Smith, ibid, p. 697.

21. D. Aitken, P. J. Goodhew and M. B. Waldron, Nature, Physical Science 244, 15 (1973).

22. D. G. Martin, U.K. A. E. A. Report CLM-R103 (1970).

23. J. L. Straalsund, H. R. Brager and J. L. Holmes, in Radiation-Induced Voids in Metals, CONF-710601, edited by J. W. Corbett and L. C. Ianniello, p. 142, National Technical Information Service, Springfield, Virginia (1972).

24. G. P. Walters, in Voids Formed by Irradiation of Reactor Materials, Eds. S. F. Pugh, M. H. Loretto, and D. I. R. Norris, p. 231, British Nuclear Energy Society, London (1971).

25. M. Kaminsky and S. K. Das, Appl. Phys. Lett. 23, 293 (1973).

26. M. Kaminsky and S. K. Das, Appl. Phys. Lett. 21, 443 (1972).

27. J. T. D. Mitchell and J. A. Booth, in Ref. 3, p. 125.

28. G. I. Kulcinski, R. G. Brown, R. G. Lott and P. A. Sanger, Trans. Am. Nucl. Soc., 17, 133 (1973). 